\title{
BMJ Open Can we talk about price with patients when choosing antiretroviral therapy? A survey with people living with HIV and prescribers in France
}

\author{
Emmanuelle Papot (D) , ${ }^{1,2}$ Nikos Kalampalikis, ${ }^{3}$ Marjolaine Doumergue, ${ }^{3}$ \\ Fabrice Pilorgé, ${ }^{4}$ Guillemette Quatremère, ${ }^{4}$ Yazdan Yazdanpanah, ${ }^{1,2}$ Marie Préau, ${ }^{5}$ \\ ANRS-GOTA study group
}

To cite: Papot E, Kalampalikis N, Doumergue $\mathrm{M}$, et al. Can we talk about price with patients when choosing antiretroviral therapy? A survey with people living with HIV and prescribers in France. BMJ Open 2021;11:e046212. doi:10.1136/ bmjopen-2020-046212

- Prepublication history and additional supplemental material for this paper are available online. To view these files, please visit the journal online (http://dx.doi.org/10.1136/ bmjopen-2020-046212).

Received 25 0ctober 2020 Accepted 27 October 2021

Check for updates

(C) Author(s) (or their employer(s)) 2021. Re-use permitted under CC BY-NC. No commercial re-use. See rights and permissions. Published by BMJ.

${ }^{1}$ Université de Paris, INSERM, IAME, F-75006, INSERM, Paris, France

${ }^{2}$ AP-HP, Hôpital Bichat, Infectious and Tropical Diseases Department, F-75018 Paris, France

${ }^{3}$ GRePS EA 4163, Université Lumière Lyon 2, Bron, France

${ }^{4}$ AIDES, Pantin, France

${ }^{5}$ UMR 1296 « Radiations :

Défense, Santé, Environnement

», Université Lumière Lyon 2,

Institut de Psychologie, Bron, France

Correspondence to

Dr Emmanuelle Papot

emmanuelle.papot@inserm.fr

\section{ABSTRACT}

Objective The aim of this study was to evaluate people living with HIV (PLWH) and HIV specialist prescribers' perception of discussing antiretroviral therapy (ART) price in PLWH's care and the acceptability of choosing or switching to various types of less expensive ARTs.

Design Cross-sectional surveys (one in a convenience sample of PLWH and one in a voluntary response sample of HIV specialist prescribers).

Setting and participants The surveys were conducted among PLHW attending an HIV clinic in the North of Paris (cohort of 4922 PLWH in 2016), and HIV specialists working in French HIV clinics (210 across 12 districts/28), between January and June 2016.

Method Self-administered questionnaires were constructed using data collected during focus groups with PLWH and prescribers. Pretests were carried out to select the questions and items. Descriptive analyses of the 129 complete questionnaires of PLWH and 79 of prescribers are presented.

Results Among PLWH, 128/129 were on ART and 54\% (69/128) gave a fair estimation of the price of their current regimen. Among prescribers, 24\% (19/79) thought that their patients knew this price. Taking into account the price of ART was not perceived as a negative step in the history of French response to HIV epidemic for $53 \%$ (68/129) of PLWH and $82 \%$ (65/79) of prescribers. Seventy-seven PLWH $(60 \%)$ would agree to switch to less expensive antiretroviral regimens (as effective and with similar adverse events) if pills were bigger; 42 (33\%) if there were more daily doses, and 37 (29\%) if there were more pills per dose; prescribers were more circumspect.

Conclusion A high proportion of PLWH gave a fair estimate of their ART price and this seemed unexpected by HIV specialists. Consideration of drug prices when choosing ART was perceived as conceivable by PLWH and prescribers if effectiveness and tolerance were also considered.

\section{INTRODUCTION}

A wide variety of effective and well-tolerated antiretroviral drugs are currently available. Prescribers can choose combinations of antiretroviral therapy (ART) which are
Strengths and limitations of this study

- These surveys explore both the people living with HIV (PLWH's) and prescribers' knowledge, beliefs and practice of antiretroviral therapy (ART) prescriptions and their prices, beyond the concept of generics.

- They were administered at a time when French National Health Insurance and French expert panel guidelines began to consider stronger recommendations for economic considerations through prescribing generics when available or when choosing maintenance regimens.

- A large cohort of PLWH is followed up in Bichat Clinic in the North of Paris where ART was a major expense in outpatients budget items, and the PLWH questionnaire was conducted in this site to develop adapted tools to discuss ART choice and price, ahead of any policies to switch ART for economic reasons.

- To avoid any misunderstanding and anxiety in PLWH, convenient sampling was based on physicians proposing the questionnaires to their patients when deemed harmless and on the availability of a social researcher, this important strategy could limit the size of the convenient sample.

- HIV prescribers across France were reached through their individual professional email address provided by their regional organisation if the organisation agreed to participate when approached through the French HIV/AIDS Society, meaning all HIV prescribers practising in France were not contacted.

appropriate to individual people living with HIV (PLWH). In parallel, HIV has now become a chronic disease with lower morbidity and mortality. ${ }^{12}$ Lifetime cost of care for PLWH has increased with around three-fourths of this cost related to ART. ${ }^{3}$ In Paris hospitals, HIV drugs are one of the three drug classes prescribed for outpatients with the highest impact on the National Health Insurance (NHI) budget. ${ }^{4}$ In France, 
most PLWH have access to ART free of charge under the 'long-term illness' status (affection longue durée), ${ }^{5}$ or through universal health coverage (couverture médicale universelle) ${ }^{67}$ funded through the NHI system. ARTs are distributed in public hospital or private pharmacies. In addition, an emergency coverage (permanence d'accès aux soins) enables persons with no administrative status to access ART. ${ }^{8}$ Consequently, as in many countries, policy-makers are now pushing to consider drug prices when selecting preferred regimens. ${ }^{10}$

In France, the price of an antiretroviral regimen is now listed as a criterion when choosing an ART, although the major criteria for treatment choice remain efficacy, adverse events and convenience. ${ }^{11}$ In 2016, the generic antiretrovirals available were zidovudine, lamivudine, nevirapine and efavirenz. They were considered to be associated with higher adverse event frequencies and/or were not commonly used apart from fixed-dose combinations. Recently, generics of more frequently used drugs like emtricitabine/tenofovir disoproxil fumarate and lamivudine/abacavir have become available. Drugsparing strategies could, in addition, reduce the price of ART. ${ }^{12}$ But both the use of generics or drug-sparing strategies to reduce costs may involve an increase in the number of pills to be taken by PLWH and, hypothetically, impact adherence to treatment, which is a cornerstone of efficacy and prevention of failure. ${ }^{13}$ While evaluating the safety and the budget impact of such hypothetical switches to less expensive ART (using generics or drugsparing regimens), it is also important to assess the acceptability of these switches, and their consequences to PLWH and prescribers.

In 2013, prices of first-line options were introduced in the French guidelines for the management of PLWH. In later editions, switch considerations of successful ART for economic reasons were stated. The guidelines also introduced regimens with a reduced number of drugs in switch strategies for virologically suppressed persons, to prevent long-term adverse events. ${ }^{11}$ These guidelines are not mandatory, although strongly advised, as practice guidelines. This introduction of a 'price' criterion for ART selection urges the prescribers to act: first through treatment optimisation and now through choosing dual agent generic pills thus breaking existing branded singletablet regimens for treatment initiation. ${ }^{11}$ During the launching of these guidelines and in subsequent updates, to our knowledge, no survey had studied what PLWH and prescribers thought about the 'price' as a selection criterion for ART and how they thought it should be tackled during a consultation to preserve the quality of the patient-physician relationship. By contrast with other settings, and maybe due to the access to treatment free of charge, physicians in France appeared not to be used to talking about prices with their patients when choosing drugs; thus it was interesting to assess if these particular circumstances were an obstacle to the implementation of the new 'price criterion' or if it was only a lack of choice or knowledge.
Our objectives were to evaluate, first, the knowledge, beliefs and practices of PLWH and HIV specialist prescribers regarding the prices of ART; then, the acceptability of the introduction of price in a consultation; and finally, based on this, to create tools to help PLWH and prescribers talk about prices.

\section{METHODOLOGY}

\section{Design, setting and participants}

We implemented a monocentre cross-sectional survey for PLWH and a multicentre (to increase the study sample size) cross-sectional survey for prescribers, based on anonymous semi-quantitative questionnaires, to assess the knowledge, beliefs and practices regarding ART and ART price among PLWH followed-up in a French University Clinic and among HIV specialists providing care in France.

The 4922 PLWH regularly followed-up at the Bichat Claude Bernard University Hospital, Paris, ${ }^{14}$ aged at least 18 years old, and who knew sufficient French to complete the questionnaire, could be included. This was a convenient sample which came from PLWH who attended the clinic for their follow-up appointment between 30 January and 30 April 2016, who were informed by their specialist about this survey, and who gave their verbal consent to participate, at a time when a social researcher was on site to assist with the questionnaire (paper or online). A voluntary response sample came from HIV specialists who were reached through the mailing list of the French HIV/AIDS Society (Société Française de Lutte contre le SIDA) between 1 March 2016 and 30 June 2016 and who consented by proceeding to the online self-administered questionnaire after reading the information.

\section{Patient and public involvement}

A multidisciplinary team of social-psychology researchers and medical researchers built the two questionnaires (one for PLWH, one for prescribers) that could answer the research questions. First, focus groups were organised separately with PLWH and HIV specialists at Bichat Hospital clinic, they studied how prescribers or PLWH tackled the notion of price when talking about ART. ${ }^{15} 16$ Next, with the help of community workers and researchers, we pretested the different potential items on the two population samples to focus on relevant and more consistent questions to assess respondents' knowledge, beliefs and practices. ${ }^{15}$ During the focus groups and pretest, we asked participants (patients from Bichat HIV clinic and community representatives who were involved in patients' support at Bichat HIV clinic) if they would agree to be contacted after the questionnaires analyses to help us develop tools to facilitate patient-prescriber conversation around price when choosing ART.

\section{Questionnaires and statistical analysis}

The questionnaires are provided in online supplemental files S1 and S2. 
To assess respondents' knowledge, beliefs and practices, a five-point Likert type scale was used (strongly disagree/disagree/uncertain/agree/strongly agree) or yes/no questions. In addition, multiple choice questions and open-ended questions were added to assess the knowledge and profile of respondents. We asked participants the price of their ART. The base price calculated with the regimen that they reported was compared with their answer, we considered that an estimate of $\pm 40 \%$ of the price stated in the French Government database in 2016 (http://base-donnees-publique.medicaments.gouv. $\mathrm{fr} /$ ) could be defined as a 'fair' estimate.

Internal consistency of the items of the different questions were measured using Cronbach's alpha reliability coefficient for Likert-type scales. It ranged from 0.47 to 0.93; we favoured sets of items with an alpha $>0.8$ for the analysis. Exact chi-squared test was used to describe differences between categorical variables, a $\mathrm{p}<0.05$ was considered significant. Missing data were displayed and dealt as 'do not know' / 'do not wish to answer'. All analyses were performed using Stata V.12.0 (StataCorp).

\section{RESULTS}

\section{Population characteristics}

One hundred and thirty-four patients (an estimate of $11 \%$ of the PLWH who may have come to the clinic on the days where the questionnaire was available and to whom their physician may have mentioned the questionnaire) were enrolled in this study. Overall, 129 questionnaires with less than $10 \%$ missing data from PLWH were collected and analysed, among which $15(12 \%)$ were completed online. Most PLWH answered to the questionnaire immediately after a visit to their HIV specialist $(112 / 129 ; 87 \%)$. Only one PLWH, newly diagnosed, was not on ART. Table 1 shows the characteristics of the respondents. Concerning the antiretroviral regimen of the 128 individuals on treatment, 113 were able to name it $(88 \%)$, 94/113 (83\%) reported being on a triple therapy, 48/94 $(51 \%)$ on single-tablet regimens, mostly integrase inhibitors $(26 / 48 ; 54 \%)$. Up to 103 (80\%) PLWH declared that they had already taken generics for other treatments than ART. None of the PLWH spontaneously highlighted the use of generics in their regimen, though 13 individuals reported the brand name of their single or combined pills which included potential generics at the time of the survey: one PLWH was on lamivudine/zidovudine combined in one brand tablet, three were on lamivudine, one was on abacavir/lamivudine/zidovudine combined in one brand tablet, three were on nevirapine, one was on efavirenz, and four were on efavirenz/tenofovir/emtricitabine combined in one brand tablet.

A total of 79 questionnaires were filled in by prescribers with a proportion of missing data less than $10 \%$, and therefore, were analysed (response rate $38 \%$ of the 210 contacted). Twenty (25\%) of the respondents worked in the Bichat Hospital. The median age was 47.5 years old $(\mathrm{IQR}=35-55)$, most of them were women $(47 ; 60 \%)$. Few had a university position (12; 15\%), 34 (43\%) had worked for more than 20 years in HIV, $22(28 \%)$ had worked in a resource-limited country, and 20 (25\%) were involved in patients support groups.

\section{The knowledge of ART price}

Among the 128 PLWH on ART: 123 (96\%) gave names for the drugs of the antiretroviral regimen they were taking (brand or molecules), of whom $113(88 \%)$ gave a correct drug name; 84 (66\%) declared they knew the price of their ART, and 69 (54\%) gave a 'fair' estimation of that price (figure 1). Of PLWH who reported knowing the cost of their ART, 40 out of $84(48 \%)$ said they were informed by noticing it in their Health Insurance report, 26 by pharmacists $(31 \%)$ and 3 by their physician $(4 \%)$. Neither the participants who have a 'Standard' health insurance nor the ones who have a 'Resource constricted' health insurance have to pay for antiretrovirals; a confounder in the difference of reported knowledge of ART price (table 1) may be that the socioeconomic situation of the latter is more difficult (more have a low 'financial well-being' and are born outside France). Overall, 19 (24\%) prescribers estimated that their patients knew the price of their ART.

\section{Can we talk about price when choosing an ART?}

One hundred and two out of 129 (79\%) PLWH agreed that their HIV specialist should know the cost of ART, and 68 prescribers $(86 \%)$ did not think that talking about the price of ART would harm the PLWH's trust. Both PLWH (72; $56 \%)$ and prescribers $(46 ; 58 \%)$ agreed that if the price is a criterion in the choice of antiretrovirals this must be clearly stated during the consultation. Sixty-eight PLWH $(53 \%)$ and 65 prescribers $(82 \%)$ disagreed that taking into account the price of ART is a negative step in the history of HIV response.

During their consultation, 5/79 prescribers reported they never look at ART price, 11 seldom look at it, 36 $(46 \%)$ look from time to time, $26(33 \%)$ often look at it and one systematically looks at the price of ART. When asked, 53/79 $(67 \%)$ prescribers stated that it would be useful to find more user-friendly reference tools to find the price of ART; 44/53 gave examples of what they thought was more adapted and 31/44 cited an interactive frequently updated website, prescription software or App.

\section{Barriers and facilitators to accepting or prescribing a less expensive regimen}

When assessing how the discussion about a less expensive treatment (as effective and with equivalent adverse events) should be approached, 98 (76\%) of PLWH declared it would be more acceptable if their prescribers proposed the switch to a less expensive treatment than if the switch was made mandatory by an external party (48; 38\%). Seventy-seven PLWH/129 (60\%) would agree to switch to less expensive ART regimens (as effective and with similar adverse events) if the new less expensive regimen was with bigger-sized pills; 42 (33\%) if the new less expensive regimen had more daily doses, and 37 
Table 1 Characteristics of PLWH (people living with HIV) sample that answered the questionnaire (n (\%); N=129 PLWH) and their answers when asked if they knew the monthly price of their treatment ( $N=128$ as one was not on antiretroviral treatment)

\section{'Do you know the monthly price of your ART?'}

Characteristics ( $N=128$ as one PLWH was not on ART at the time of the survey)

of the sample Answers*:

$(\mathrm{N}=129 ; \%) \quad$ Yes $(\mathrm{n}, \%)$

\begin{tabular}{lcr}
\hline Age (years) & $28(21.7)$ & $15(55.6)$ \\
\hline 20-39 years & $79(61.3)$ & $53(67.1)$ \\
\hline $40-59$ years & $19(14.7)$ & $15(79.0)$ \\
\hline 260 years & $3(2.3)$ & $1(33.3)$ \\
\hline Do not wish to answer & & \\
Sex & $84(65.1)$ & $59(70.2)$ \\
\hline Male & $45(34.9)$ & $25(56.8)$ \\
\hline Female & & \\
Place of birth & $70(54.3)$ & $57(81.4)$ \\
\hline France & $35(27.1)$ & $15(44.1)$ \\
Sub-Saharan Africa & $19(14.7)$ & $9(47.4)$ \\
\hline Others $\dagger$ & $5(3.9)$ & $3(60.0)$ \\
\hline Do not wish to answer
\end{tabular}

Living as a couple

\begin{tabular}{|c|c|c|}
\hline Yes & $63(48.8)$ & $45(72.6)$ \\
\hline No & $66(51.2)$ & $39(59.1)$ \\
\hline \multicolumn{3}{|l|}{ Having children } \\
\hline Yes & $66(51.2)$ & $38(58.5)$ \\
\hline No & $63(48.8)$ & $46(73.0)$ \\
\hline \multicolumn{3}{|l|}{ Do you consider yourself as } \\
\hline MSM & $54(41.8)$ & $42(77.8)$ \\
\hline Heterosexual & $65(50.4)$ & $39(60.9)$ \\
\hline Do not wish to answer & $10(7.8)$ & $3(30.0)$ \\
\hline \multicolumn{3}{|l|}{ Education } \\
\hline No qualification & $17(13.2)$ & $10(58.8)$ \\
\hline Lower secondary school diploma & $27(20.9)$ & $15(57.7)$ \\
\hline High school diploma & $17(13.2)$ & $11(64.7)$ \\
\hline University degree & $68(52.7)$ & $48(70.6)$ \\
\hline \multicolumn{3}{|l|}{ In employment } \\
\hline Yes & $86(66.7)$ & $58(67.4)$ \\
\hline No & $43(33.3)$ & $26(61.9)$ \\
\hline \multicolumn{3}{|l|}{ Financial well-being } \\
\hline Very difficult & $44(34.1)$ & $24(55.8)$ \\
\hline Somewhat difficult & $34(26.4)$ & $26(76.5)$ \\
\hline Not difficult & $48(37.2)$ & $33(68.8)$ \\
\hline Do not wish to answer & $3(2.3)$ & $1(33.3)$ \\
\hline \multicolumn{3}{|l|}{ Disabled persons' allowances } \\
\hline Yes & $19(14.7)$ & $11(57.9)$ \\
\hline No & $98(76.0)$ & $66(68.0)$ \\
\hline Do not know & $12(9.3)$ & $7(58.3)$ \\
\hline \multicolumn{3}{|c|}{ Time since diagnosis of HIV infection (years) } \\
\hline $0-9$ & $59(45.7)$ & $36(62.1)$ \\
\hline
\end{tabular}


Table 1 Continued

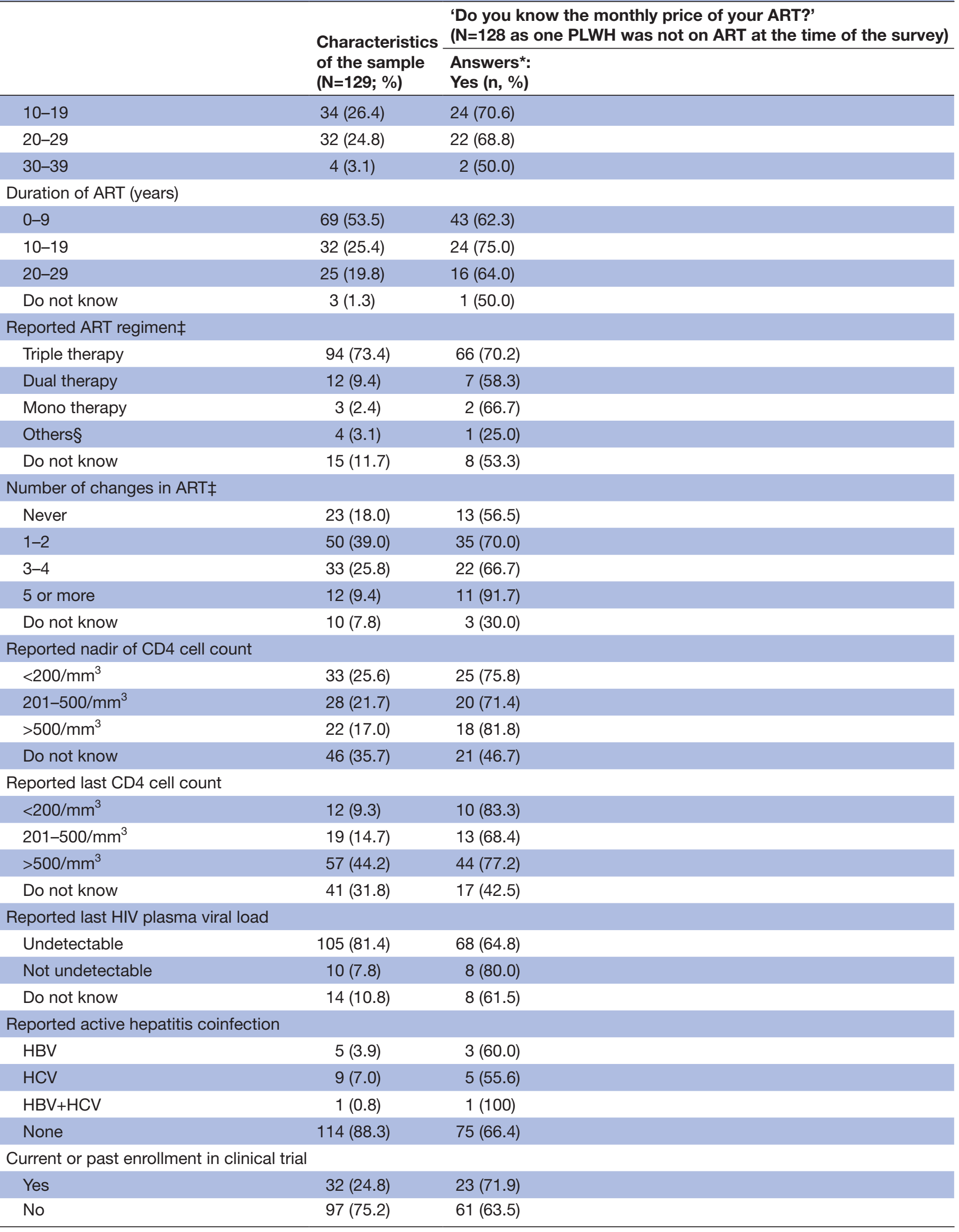




\begin{tabular}{|c|c|c|}
\hline & \multirow{2}{*}{$\begin{array}{l}\text { Characteristics } \\
\text { of the sample } \\
(\mathrm{N}=129 ; \%)\end{array}$} & $\begin{array}{l}\text { 'Do you know the monthly price of your ART?' } \\
\text { ( } N=128 \text { as one PLWH was not on ART at the time of the survey) }\end{array}$ \\
\hline & & $\begin{array}{l}\text { Answers*: } \\
\text { Yes (n, \%) }\end{array}$ \\
\hline \multicolumn{3}{|l|}{ Health Insurance status } \\
\hline Standard & $99(76.7)$ & $70(70.7)$ \\
\hline Yes & $103(79.8)$ & $76(73.8)$ \\
\hline No & $26(20.2)$ & $8(32.0)$ \\
\hline \multicolumn{3}{|c|}{ Contact with PLWH's associations } \\
\hline Yes & $15(11.6)$ & $8(53.3)$ \\
\hline
\end{tabular}

*Answers could be either 'yes' or 'no', 84/128 answered 'yes'.

†Others=rest of Europe, Caribbean, North Africa, South America, South-East Asia, Far East.

$\ddagger \mathrm{N}=128$, as 1 out of the 129 respondents was not on ART.

§Others=multiple therapy and currently on clinical trials' ARV drugs.

ๆStandard: French Social Security+additional private coverage and French Social Security coverage alone.

**Universal Health Coverage (CMU)+top up CMU, State medical aid (AME) and Hospitals access to Healthcare (PASS) for people excluded from health insurance.

AME, aide médicale de l'état; ART, antiretroviral therapy; CMU, Couverture médicale universelle; HBV, hepatitis B virus; HCV, hepatitis $\mathrm{C}$ virus; HIV, human immunodeficiency virus; MSM, men who have sex with men; PASS, Permanence d'accès aux soins; PLWH, people living with HIV.

$(29 \%)$ if the new less expensive regimen came with more pills per dose (figure 2). For the $110 \mathrm{PLWH}$ for whom the regimen was known (excluding the three in a clinical trial), there were no significant differences in the willingness to switch for economic reasons (whether it was a switch to bigger pills or to more daily doses or a switch to more pills per dose) between PLHW on single-tablet regimens ( $n=48 ; 71 \%$ (34/48), 23\% (11/48), 31\% (15/48) agreed, respectively) and PLHW reporting a multipletablet regimen $(n=62 ; 53 \%(33 / 62), 32 \%(20 / 62), 27 \%$ $(17 / 62)$ agreed, respectively). We explored the potential apprehension associated with a switch (implying to any type of regimen including generics and/or de-simplifying to more pills): $83(64 \%)$ of the 129 PLWH declared they still fear new adverse events at each switch of ART, and 62 (48\%) fear less efficacy. Most PLWH answered they did not know if less expensive ART were less convenient or had more adverse events, $(58 ; 45 \%$ and $56 ; 43 \%$, respectively). They even tended to disagree that less expensive ARTs were less convenient or had more adverse events (60; $47 \%$ and $57 ; 44 \%$, respectively), only $8 \%$ and $13 \%$ agreed with these statements, respectively.

Seventy-eight (99\%) prescribers answered 'yes' when asked if it would be acceptable to switch to less expensive ART regimens (with equivalent efficacy and adverse events). Prescribing a less expensive antiretroviral regimen was found to be more acceptable in the case of a switch for simplification $(73 / 79 ; 92 \%)$, than in the

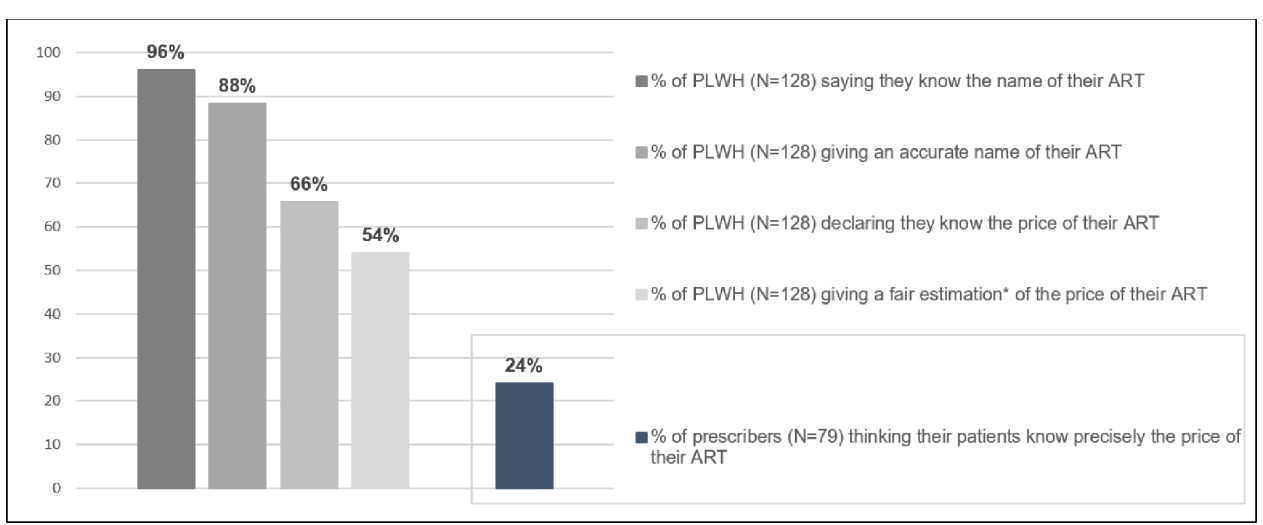

Figure 1 Answers from PLWH and prescribers about knowledge of one's own ART name and price. *'Fair' estimation=base price calculated with the regimen reported $\pm 40 \%$. ART, antireroviral therapy; PLWH, people living with HIV. 


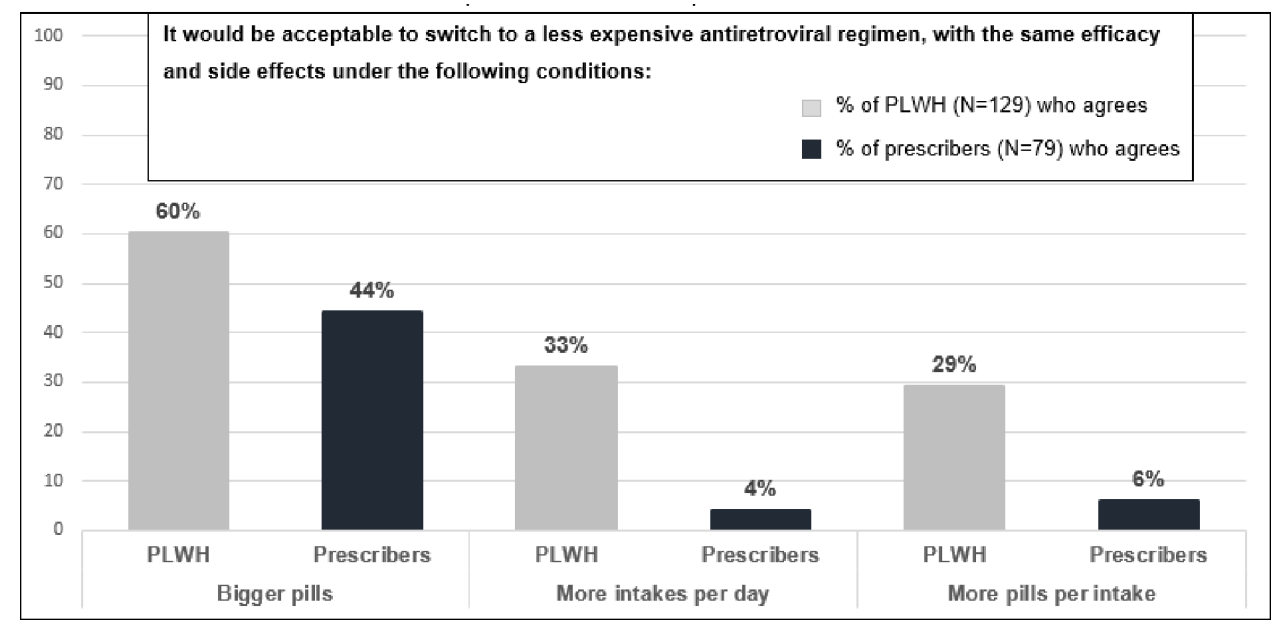

Figure 2 Answers from PLWH (people living with HIV) and prescribers about the acceptability of switching for economic reasons with different consequences in terms of pill burden. PLWH, people living with HIV.

case of initiation $(67 ; 85 \%)$, or in the case of a change for failure or adverse event $(59 ; 74 \%)$. Thirty-five (44\%) prescribers would agree to switch their patients' antiretroviral regimen to a less expensive one (as effective and with similar adverse events) if the switch was to bigger pills; $3(4 \%)$ if the new less expensive regimen implied more daily doses, and $5(6 \%)$ if the new less expensive regimen was with more pills (figure 2). Only 13/79 (17\%) HIV specialists thought that their patients feared negative consequences when switching ART, and 22 (28\%) HIV specialists declared that they did not know.

\section{DISCUSSION}

This study assessed PLWH and HIV prescribers' beliefs, representations and acceptability of potential ART switches for economic reasons, in France. In contrast to previous studies that have mostly concentrated on antiretroviral generics, we focused on a wider perspective because the decrease of cost of ART prescription in HIV practice is not only achievable with generics. For example, potential switches, adapted to PLWH's medical and HIV history, to less expensive antiretroviral regimens like class-sparing strategies, may be as economical as switches to current generics. ${ }^{12}$ These strategies may imply interventions such as splitting single-tablet regimens. In our survey, a high proportion of PLWH knew the price of their ART and this was not what HIV specialists perceived. It showed that a non-negligible proportion of PLWH would accept switching their ART for economic reasons even if the size and the number of pills increased, up to one third would agree even if there were more daily doses. However, increasing the pill burden was a concern for a high proportion of prescribers. In contrast, PLWH respondents feared treatment switches, and they tended to be less convinced than HIV specialists that taking the price into account when choosing ART regimens was not a negative step in the history of HIV care. However, both PLWH and prescribers agreed that if the price was to be considered it should be stated clearly during the consultation. We found that there were specific time points during patients' trajectories where changes involving 'economics' may be more acceptable (ie, simplification rather than failure). Also, PLWH seemed more inclined to accept switches if proposed by their prescribers rather than if it was mandatory.

Jacomet $e t a l^{17}$ carried out a survey in France on the perception of ART generics by PLWH and their HIV specialists. The trends regarding acceptance were the same in our study in relation to increasing pills and/ or doses, with the important exception that we found prescribers more conservative than patients. This could be explained by the broader scope of our questions considering less expensive treatment, whether optimisation or generics. An Irish survey on PLWH's and healthcare providers' perception of generic substitution, Kieran et $a l^{18}$ also found that switches would be less accepted by both populations if the pill burden was increased.

In a real-life setting, Krentz et al proposed to PLWH, in Canada, to switch from the brand pill of dolutegravir/ abacavir/lamivudine to generic abacavir/lamivudine and dolutegravir brand pill for economic reasons (excluding PLWH with poor adherence), 55\% agreed; PLWH initiating ART were also upfront proposed the multiple-tablet regimen and $63 \%$ agreed. PLWH who disagreed reported more concerns about the number of pills than about generics. $^{19}$

Pill burden appears central to the answers of PLWH and prescribers. Studies showed that in general singletablet regimens might have an impact on adherence to treatment, however, they failed to illustrate that these regimens were associated with a higher rate of virological efficacy; the impact seemed to be clear only in hard-to-treat patients. ${ }^{13}{ }^{20-23}$ There is a lack of evidence in high-income countries, in the long term and in reallife conditions, of the impact on one PLWH's level of adherence itself and thus on the efficacy which ensues, of splitting a single-tablet regimen to switch to a lessexpensive regimen whether for optimisation or generic 
introduction. Obviously, there are different aims when optimising, changing or initiating ART and the impact on adherence could well be different. This point is important to consider and to discuss with patients when choosing an ART regimen through a real PLWH-prescriber dialogue, where they both have an important role, to ensure acceptability and a high confidence among PLWH. It is important to guarantee an adequate adherence to ART. Engelhard $e t a l^{4}$ also illustrated in the Netherlands that PLWH were not necessarily opposed to multiple-tablet regimens instead of single ones to reduce healthcare costs, if efficacy, tolerance and number of intake were considered. We do think that taking the price into account when choosing an ART is possible and should be considered but through a shared-decision making (SDM) process. ${ }^{25}$ This 'bottom-up' approach could help to prevent a loss of adherence to treatment. SDM would help prescribers to talk about price while delivering adequate messages to PLWH on the origins of generics, the consequences of drug-sparing regimens, or other simplifications. Clucas $e t$ $a l^{26}$ have already underlined the importance of decisionmaking for high-levels of patient-physician concordance in HIV treatment.

Based on the answers of these questionnaires and the review presented above, we developed two tools. First, an interactive website (adapted for computers and smartphones) where each type and dosage of antiretroviral (branded and generic ones) could be selected individually with a timely updated price per day/month/year as well as an automated cumulated price when different molecules were chosen (based on French official database, price in Euro without taxes). Second, an SDM guide for prescribers and patients which went through the process of choosing ART and touched on price. The latter has been developed with PLWH and representatives of the community. Both tools have been implemented for 1 year in Bichat HIV clinic in 2018 and their utilisation will be assessed along with the change of prescriptions in the cohort, and the budget impact of these changes.

This study had several limitations. Regarding PLWH, the proposition to participate in this survey was at the discretion of the patient's referent physician during their usual follow-up appointment, and the physician's willingness to ask their patients to participate in a questionnaire whose goal was to talk about price was weak (even if the questionnaire was conducted by a trained social researcher). Also, we only selected PLWH who were literate in French. These points inferred a selection bias in PLWH responding to our survey. But we accepted this limitation in this exploratory study where the aim of the survey was to grasp the repositioning strategies of PLWH. Besides, we cannot evaluate PLWH acceptance rate for this survey or compare the characteristics of responders and non-responders during the study period. We do not have all the necessary data of the 4922 PLWH followed up in Bichat HIV clinic to ascertain the representativeness of the sample (129 participants). However, the sample is diverse in terms of socioeconomic background and medical history, and the translation of these findings into a SDM guide in ART regimen choice tackling prices was based on the repositioning strategy of PLWH and prescribers. The repositioning process is more generalisable and can apply more widely to help inform decisions and adherence whether a change of ART for economic reason is chosen or imposed. Finally, at the time of the survey, the context of new hepatitis $\mathrm{C}$ treatment costs was a prominent issue and may have inferred a social desirability bias, especially among prescribers.

\section{CONCLUSION}

This study illustrates that both PLWH and prescribers will agree to talk about price when choosing an ART, but trust in interventions such as prescribing generics containing regimens and class-sparing regimens must be worked on, particularly when they imply a split of a single-tablet regimen. This might be achieved through a patientprovider dialogue. Our multidisciplinary research group developed a SDM guide in ART regimen choice using these results, where price is touched on, which is currently assessed.

Acknowledgements The authors gratefully acknowledge the participation of the ANRS-GOTA Study Group. The authors also gratefully acknowledge the participation of the other academic and community-based social researchers who facilitated the survey (Sabrina Cossais, Sarah Benayoun, Isaora Rivierez, Vanessa Laguette, Clemence Fradet), and of the patients and healthcare givers who participated in the focus groups, pretests, survey and the construction of the SDM guide on ART and their price, and of the associations who reviewed it (AIDES, TrT-5).

Collaborators ANRS-GOTA Study Group: Pr Philippe Arnaud (AP-HP, Hôpital Bichat, Pharmacy, Paris, France), Claire Auger (AP-HP, Hôpital Bichat, PharmacoToxicology Department, Paris, France), Franck Barbier (AIDES, Pantin, France), Dr Gaele Bruneaux (Praticiens Conseils de I'Assurance Maladie de Paris, France), Katia Bourdic (Internal Medicine, Bicêtre University Hospital, AP-HP, Le Kremlin-Bicêtre, France), Pr Elisabeth Bouvet (AP-HP, Hôpital Bichat, Infectious and Tropical Diseases Department, Paris, France), Dr Agnès Certain (AP-HP, Hôpital Bichat, Pharmacy, Paris, France), Dr Charlotte Charpentier (AP-HP, Hôpital Bichat, Virology Department, Paris, France; Université de Paris, INSERM, IAME, Paris, France), Marjolaine Doumergue (Université Lumière Lyon 2, GRePS EA 4163, Bron, France), Véronique Doré (ANRS, Paris France), Pr Cécile Goujard (Services de Médecine interne et d'Immunologie clinique, AP-HP Université Paris-Saclay, Hôpitaux Béclère et Bicêtre; Faculté de Médecine - Université Paris-Saclay, CESP - Centre de recherche en épidémiologie et santé des populations - U1018 INSERM UPS UVSQ, Le Kremlin Bicêtre, France), Dr Sophia Guessous (Praticiens Conseils de l'Assurance Maladie de Paris, France), Dr Anne-Claire Haye (Praticiens Conseils de l'Assurance Maladie de Paris, France), Pr Nikos Kalampalikis (Université Lumière Lyon 2, GRePS EA 4163, Bron, France), Dr Roland Landman (AP-HP, Hôpital Bichat, Infectious and Tropical Diseases Department, Paris, France; Université de Paris, INSERM, IAME, Paris, France), Sylvie LeGac (AP-HP, Hôpital Bichat, Infectious and Tropical Diseases Department, Paris, France), Françoise Louni (AP-HP, Hôpital Bichat, Infectious and Tropical Diseases Department, Paris, France), David Michels (AIDES, Pantin, France; Coalition Plus, Community-based Research Laboratory, Pantin France), Pr Philippe Morlat (Internal Medicine, Saint Andre Hospital, Bordeaux University Hospital, Bordeaux University, Bordeaux, France; ISPED, Inserm, Bordeaux Population Health Research Center, Team MORPH3EUS, UMR 1219, CIC-EC 1401, Bordeaux University, Bordeaux, France), Dorothée Obach (Université de Paris, INSERM, IAME, Paris, France), Dr Emmanuelle Papot (AP-HP, Hôpital Bichat, Infectious and Tropical Diseases Department, Paris, France; Université de Paris, INSERM, IAME, Paris, France), Dr Gilles Peytavin (AP-HP, Hôpital Bichat, Pharmaco-toxicology Department, Paris, France; Université de Paris, INSERM, IAME, Paris, France), Fabrice Pilorgé (AIDES, Pantin, France), Laurence Pochat (Praticiens Conseils de l'Assurance Maladie de Paris, France), Pr Marie Préau (UMR 1296 « Radiations : Défense, Santé, Environnement », Université Lumière Lyon 2, Institut de Psychologie, Bron, France), Guillemette Quatremère (AIDES, Pantin, France), Daniela Rojas Castro 
(Coalition Plus, Community-based Research Laboratory, Pantin France; Aix Marseille University, IRD, INSERM, SESSTIM, Marseille, France), Pr Yazdan Yazdanpanah (AP-HP, Hôpital Bichat, Infectious and Tropical Diseases Department, Paris, France; Université de Paris, INSERM, IAME, Paris, France), Pr Patrick Yéni (AP-HP, Hôpital Bichat, Infectious and Tropical Diseases Department, Paris, France; Université de Paris, INSERM, IAME, Paris, France).

Contributors EP, NK, MD, FP, GQ, YY and MP contributed to the conception and design of the study. EP, NK, MD and MP constructed the questionnaires for the study. EP, NK, MD, FP, GQ, YY and MP acquired data for the study. EP performed the statistical analysis. EP, YY and MP drafted the article. All authors revised the article critically for important intellectual content. All authors read and approved the final manuscript. MP accepted full responsability for this work, had full access to all data and had final responsibility for decision to submit the article for publication.

Funding This work was supported by the French Research Agency on AIDS and Viral Hepatitis (ANRS) under grant (2014-1).

Competing interests YY received travel grants, honoraria for presentations at workshops and consultancy honoraria from Abbvie, Brystol-Myers Squibb, Gilead, Merck, J\&J and ViiV Healthcare.

Patient consent for publication Not applicable.

Ethics approval Informed verbal consent was obtained from all participants (patients) who answered the non-identifying survey as required by the IRB. Regarding the online survey for prescribers, a written information was given at the beginning of the non-identifying survey, participation was consent. The surveys are part of 'Cost of antiretroviral drug therapy' study which has been approved by Ethics Evaluation Committee of Inserm (IORG0003254FWA00005831) - Institutiona Review Board (IRB00003888) of the French Institute of Medical Research and Health (CEEI-Inserm), the French Advisory Committee on Data Processing Related with Health Research (CCTIRS) and National Commission for Data Protection and Liberties (CNIL-no 915378-09/11/2015).

Provenance and peer review Not commissioned; externally peer reviewed.

Data availability statement All data relevant to the study are included in the article or uploaded as online supplemental information. The authors confirm that the data supporting the findings of this study are available within the article and its supplementary material.

Supplemental material This content has been supplied by the author(s). It has not been vetted by BMJ Publishing Group Limited (BMJ) and may not have been peer-reviewed. Any opinions or recommendations discussed are solely those of the author(s) and are not endorsed by BMJ. BMJ disclaims all liability and responsibility arising from any reliance placed on the content. Where the content includes any translated material, BMJ does not warrant the accuracy and reliability of the translations (including but not limited to local regulations, clinical guidelines, terminology, drug names and drug dosages), and is not responsible for any error and/or omissions arising from translation and adaptation or otherwise.

Open access This is an open access article distributed in accordance with the Creative Commons Attribution Non Commercial (CC BY-NC 4.0) license, which permits others to distribute, remix, adapt, build upon this work non-commercially, and license their derivative works on different terms, provided the original work is properly cited, appropriate credit is given, any changes made indicated, and the use is non-commercial. See: http://creativecommons.org/licenses/by-nc/4.0/.

\section{ORCID iD}

Emmanuelle Papot http://orcid.org/0000-0003-2782-0263

\section{REFERENCES}

1 Cohen MS, McCauley M, Gamble TR. HIV treatment as prevention and HPTN 052. Curr Opin HIV AIDS 2012;7:99-105.

2 Bhaskaran K, Hamouda O, Sannes M, et al. Changes in the risk of death after HIV seroconversion compared with mortality in the general population. JAMA 2008;300:51-9.

3 Sloan CE, Champenois K, Choisy P, et al. Newer drugs and earlier treatment: impact on lifetime cost of care for HIV-infected adults. AIDS 2012;26:45-56.

4 Cnam. Les prescriptions hospitalières de médicaments délivrés en ville en 2016 et les évolutions depuis 2004 [Hospitals' prescriptions of drugs supplied in private pharmacies in 2016 and progression since 2004]. Points de repère $n 49$ - Les PHMEV en 2016, 2018. Available: https://assurance-maladie.ameli.fr/etudes-et-donnees/ 2018-phmev-2016-evolutions-depuis-2004

5 Chevreul K, Berg Brigham K, Durand-Zaleski I, et al. France: health system review. Health Syst Transit 2015;17:1-218.

6 Nay O, Béjean S, Benamouzig D, et al. Achieving universal health coverage in France: policy reforms and the challenge of inequalities. Lancet 2016;387:2236-49.

7 Chevreul K, Durand-Zaleski I, Gandre C. The health systems and policy monitor: France: European Observatory on health systems and policies, 2015. Available: https://www.hspm.org/countries/ france25062012/countrypage.aspx [Accessed 11 Jun 2019].

8 Georges-Tarragano C. [The permanence of access to health care: a tradition of hospitality and innovative organizational model]. Rev Med Interne 2015;36:38-41.

9 Bacha K. Permanence d'accès aux soins (PASS), un exemple de mission de l'hôpital public développer [Permanence of access to health care, an example of mission of the public hospital to develop], 2011. Available: https://solidarites-sante.gouv.fr/systeme-de-santeet-medico-social/parcours-de-sante-vos-droits/bonnes-pratiquesen-region/ile-de-france/article/permanence-d-acces-aux-soins-passun-exemple-de-mission-de-l-hopital-public-a

10 Jones R, Gazzard B. The cost of antiretroviral drugs and influence on prescribing policies. Int J STD AIDS 2006;17:499-506.

11 Morlat P, Blanc A, Bonnet F, et al. Groupe d'experts pour la prise en charge du VIH - Experts group on People Living With HIV Care, 2018. Available: https://cns.sante.fr/actualites/prise-en-charge-du-vihrecommandations-du-groupe-dexperts/

12 Papot E, Landman R, Louni F, et al. Budget impact of antiretroviral therapy in a French clinic cohort. AIDS 2017;31:1271-9.

13 Clay PG, Nag S, Graham CM, et al. Meta-Analysis of studies comparing single and Multi-Tablet fixed dose combination HIV treatment regimens. Medicine 2015;94:e1677.

14 Rapports d'activité | Corevih IDF Nord [Annual Report]. Available: http://www.corevih-idfnord.fr/rapports-d-activite/ [Accessed 3 Aug 2018].

15 Caillaud S, Kalampalikis N, Groups F. Focus groups and ecological practices: a psychosocial approach. Qual Res Psychol 2013;10:382-401.

16 Moscovici S. Le scandale de la pensée sociale: Textes inédits sur les représentations sociales réunis et préfacés par Nikos Kalampalikis [The scandal of the social thought]: Éditions de l'École des hautes études en sciences sociales, 2013.

17 Jacomet C, Allavena C, Peyrol F, et al. Perception of antiretroviral generic medicines: one-day survey of HIV-infected patients and their physicians in France. PLoS One 2015;10:e0117214.

18 Kieran JA, O'Reilly E, O'Dea S, O'Dea S, et al. Generic substitution of antiretrovirals: patients' and health care providers' opinions. Int $J$ STD AIDS 2017;28:1239-46.

19 Krentz HB, Campbell S, Lahl M, et al. De-simplifying single-tablet antiretroviral treatments: uptake, risks and cost savings. HIV Med 2019;20:214-21.

20 Bangsberg DR, Ragland K, Monk A, et al. A single tablet regimen is associated with higher adherence and viral suppression than multiple tablet regimens in HIV+ homeless and marginally housed people. AIDS 2010;24:2835-40.

21 Nachega JB, Parienti J-J, Uthman OA, et al. Lower pill burden and once-daily antiretroviral treatment regimens for HIV infection: a meta-analysis of randomized controlled trials. Clin Infect Dis 2014:58:1297-307.

22 Cotte L, Ferry T, Pugliese P, et al. Effectiveness and tolerance of single tablet versus once daily multiple tablet regimens as first-line antiretroviral therapy - Results from a large french multicenter cohort study. PLoS One 2017;12:e0170661.

23 Engsig FN, Gerstoft J, Helleberg M, et al. Effectiveness of antiretroviral therapy in individuals who for economic reasons were switched from a once-daily single-tablet regimen to a triple-tablet regimen. J Acquir Immune Defic Syndr 2014;66:407-13.

24 Engelhard EAN, Smit C, Vervoort SCJM, et al. Patients' willingness to take Multiple-Tablet antiretroviral therapy regimens for treatment of HIV. Drugs Real World Outcomes 2016;3:223-30.

25 Stiggelbout AM, Pieterse AH, De Haes JCJM, . Shared decision making: concepts, evidence, and practice. Patient Educ Couns 2015;98:1172-9.

26 Clucas C, Harding R, Lampe F. Doctor-Patient concordance during HIV treatment switching decision-making: concordance in HIV switching decisions. HIV Medicine 2011;12:87-96. 